ISBN 978-93-86878-09-0

10th International Conference on Language, Humanities, Education and Social Sciences

(ICLHESS-18)

Bali (Indonesia) Jan. 12-13, 2018

\title{
Safety and Human Vulnerability: A Philosophical Consideration
}

\author{
Emir Bosnic \\ Estacio de Sá University, Rio de Janeiro, Brasil
}

\begin{abstract}
This study has as its theme the relationship between safety and human vulnerability. The central issue concerns the approach to safety from the perspective of the human vulnerability. The intention is to show how human vulnerability determines the understanding of the safety problem and the construction of the concept of safety itself. The human vulnerability is considered and defined in philosophical terms. Like this, the study offers the analysis of the safety aspects investigated from the perspective of human vulnerability. The following aspects are analyzed: the human factor as the key to safety, the freedom and safety ethics. It is concluded that any discourse and practice related to the safety issue involve analysis based on human vulnerability. This means to recognize and understand that the human being is the ultimate reason for any policy and measure implemented to ensure safety in all spheres and in all aspects of life, from the individual to the international context..
\end{abstract}

Keywords: safety, human vulnerability, exposure to Others, freedom, safety ethics

\section{Introduction}

How should we understand safety? The shearch for the answer involves the need to choose the perspective to be used in an attempt to understand safety. The perspective chosen determines the course and nature of the attempt to understand safety and the possibility of constructing a concept to be applied both in theory and practice. In this study, the chosen perspective refers to the human vulnerability. It means that safety should be addressed on the horizon of human vulnerability. The question above becomes more specific and takes the following form: how should safety be understood from the perspective of human vulnerability?

For this reason, the focus of this study is to examine the relationship safety- human vulnerability. The purpose of such investigation is to know how human vulnerability determines the understanding of the safety problem and the construction of the concept of safety. The intentation is to show how human vulnerability determines the course and nature of the understanding of safety. In order to fulfill this intention, the study is composed of two main parts that deal with the following subjects: the concept of human vulnerability and the safety considered from the perspective of human vulnerability. In the first part, we identify the central issues in the attempt to define the concept of human vulnerability in philosophical terms. As for the second part of the study, we show how this concept determines the possibility of the understanding of safety as a subject investigated in theory and approached in everyday life (from the daily life of an individual to the global context).

\section{The Concept of Human Vulnerability}

What is it understood as "vulnerability"? Everyday life shows that "vulnerability" has many meanings applied in different situations (Busumtwi-Sam, 2008:2). There is likewise a wide variety of concepts used in academic studies ${ }^{1}$ and in practices at all levels (from an individual's life to the international and global context).

1

Henk ten Have (2015, pp. 396), Center for Healthcare Ethics (Duquesne University, USA), presented a history of the use of the concept of vulnerability in academic studies. According to him, before the 1970 s, the concept was used in the context of general medicine. Since 1976 , the concept has been used in the context of professional relations, human development, violence and crime, social conditions and discourse on developing countries. In 
But it is not only about presenting and discussing the variety and content of concepts of human vulnerability in use both in theory and in practice. The point is to build a concept that can to contribute to the understanding of the relationship between safety and human vulnerability. In this study, it is the concept built in terms of philosophy.

The concept built in philosophical terms defines human vulnerability as an unavoidable dimension of human existence. It is a dimension linked to the fact that the human being exists in the world e relates to the Other. In this way, the possibility of suffering injury becomes an inescapable dimension of its existence. Human being is unavoidably vulnerable. He creates his own vulnerability through relationship with the Other e the world. In this context, the human vulnerability is not defined in terms of weakness. At this point it is important to emphasize that the philosophical consideration does not regard weakness as a means to define the man in terms of existential fragility and insecurity. It highlights the fact that human existence understands vulnerability as an unavoidable dimension built in man's relationship with the Other and the world.

Analyzing the vulnerability concept presented above. The analysis focuses on three central points of the concept in question: exposure to the Other, the ethical responsibility, and the two types of behavior related to vulnerability: solidarity and violence.

As it has been said before, vulnerability arises in man's relationship with the Other. This rtelationship menas exposure to the Other. Lévinas (1974, pp. 94) called such exposure by the name of sensitivity. In order to understand human vulnerability, it is necessary to focus on sensitivity and analyze how it is as exposure to the Other. Sensitivity is constituted "in the inevitable orientation of the being 'from oneself' to the 'Other'" (Lévinas, 1971, pp. 237). Orienting oneself to the Other understands exposure to the Other. It is an inevitable trait of human existence. According to Lévinas (1974, pp. 94), sensitivity leads to vulnerability. This says that vulnerability is constituted through sensitivity, as an unavoidable dimension of human existence. To exist as a human being is to orient oneself to the Other. That means living in the condition of human vulnerability as an unavoidable dimension of man's existence.

Sensitivity analysis shows that exposure to the Other involves mutual dependence on each other. In mutual dependence, people depend on us. We have the "responsibility for the people who depend on us" (Misztal, 2011, pp. 63). It is the ethical responsibility: to be aware that my vulnerability is linked to the vulnerability of the Other and to adopt behavior that will not harm the dignity, integrity and freedom of the Other by acting in favor of the human being as the ultimate reason for safety. It also understands the necessity to help those who need it ${ }^{2}$. In relationship with the Other, the human vulnerability leads to the question of ethical responsibility.

In everyday life, the very human vulnerability may suggest the kind of behavior that will be accomplished in the pursuit of safety. These are the two types of behavior: solidarity and violence. Recognizing the Other's vulnerability and connecting it with "my own vulnerability, confirming our shared hardship in the world can lead to solidarity and the affirmation of human rights" (Geddes, 2015, pp. 400). Vulnerability is recognized as shared and seen as an opportunity for union and cooperation in trying to solve problems that affect the lives of people and the whole society. But there is another possibility of recognizing the vulnerability of the Other. This is vulnerability faced with my sense of safety and recognized as a threat. This time the vulnerability of the Other is not seen as shared. On the contrary, it is confronted with my vulnerability and my sense of safety. The result of this confrontation takes the form of violence, used with the purpose of sustaining, maintaining and preserving my own safety. The vulnerability of the Other is the threat that must be eliminated ${ }^{3}$. Intolerance towards those

the 1990s, the same concept was related to climate change, the degradation of the environment, human rights and natural resources. Finally, in the 2000s, the concept is used in discourses about human safety and bioteirorism. As we can see, there has been an increase in the use of the concept of vulnerability.

${ }^{2}$ In the international context, we have the idea and the practice of the responsibility to protect. This responsibility means protecting the dignity, integrity, and freedom of those who need help to survive and live as human beings.

The practice of responsibility to protect shows the complexity and difficulty of building mutual dependence that does not detract from the dignity, integrity and freedom of exposed persons (sensitivity). That is to say, it shows the complexity and difficulty of guaranteeing security for all human beings.

${ }^{3}$ With this in mind, we suggest investigating the refugee crisis in Europe as an example for the basis of the vulnerability recognized as the threat. It is an approach that can contribute to the clarification of aggressive behavior towards refugees. Undoubtedly, those who show intolerance and aggressiveness depart from their sense of safety and recognize the vulnerability of others (refugees) as the threat that must be eliminated by extreme and violent measures. 
who are not "ours", racist behavior, hatred based on ethnic and religious aspects, fights between people in everyday life are examples of events related to the recognition of human vulnerability as a threat. Both from the perspective of safety practices and human vulnerability, concerns about violence and the use of force are increasing for the individuals, the civil society and the international community. The questions to which they seek answers are: what measures are applied in safety practices and who will be reached by them? The transparency of safety policies? What are the real effects of the measures implemented and the policies adopted? How long will the measures taken last? What is the source of insecurity? As violence is part of the safety practices, these issues arise as inevitable and necessary in the world in which the human being seeks a safe and better daily life.

Here we end our discussion of the concept of human vulnerability. It is the same concept to be used in the analysis of safety the light of human vulnerability.

\section{Safety from the Perspective of the Human Vulnerabilility}

We use a concept that defines safety as a "fundamental structure" of human existence (Heidegger, 1996: 7). The term "fundamental structure" indicates "the basic constitution" of human existence and the meaning that the same constitution has for the man in every day life ${ }^{4}$. Keeping in mind this term, it possible to say that the safety as "the basic constitution" of human existence refers to the absence and the meaning of treat and vulnerability in everyday life. The meaning in question is manifested by the intention to promote and pursue safety. The idea of such an intention is also included in the concept of safety.

This concept is analyzed from the perspective of the of human vulnerability. The core of safety is the human vulnerabilidade (Cohn, 2013, pp. 51). In this perspective, the analysis refers to the following aspects of safety: the human factor as the key to safety, safety ethics and the issue of freedom. From the perspective of human vulnerability, the human being is positioned as the ultimate reason for safety. Humans are seen as "the analytical central unit and the ultimate referent for safety" (Burke, Lee-Koo and McDonald, 2016, pp. 9). The human beings are fundamental to safety in the sense of being the biggest concern and the ultimate reason for their own security.

Before continuing the analysis of the indicated factor, it is reasonable to mention that the term 'human being' appears too general and too abstract (without specifications that determine its meaning). In our study, we have specified the term in the sense of indicating a structure, called "man," characterized by vulnerability as an unavoidable aspect of his very own existence. It is an aspect that lies behind all situations and activities of any individual, community, social group, organization, or state. There are many times in speeches and in practices that this aspect is not seen, which leads to forgetting that man is behind everything constructed in the human life (from the individual to the state). Such oblivion in the area of safety raises the following question: Is the human being the central subject of policy and measures implemented to ensure safety? The search for safety should include this question as the starting point, but also as something permanent present in the attempt to achieve the desired absence of treat and vulnerabilidade in everyday life.

Going back to the theme of human being as the key to safety. Observed from this perspective, the search for safety should avoid three critical situations that deny this factor. One of them refers to the discourse that mentions the human being as the focus, but there is a gap ${ }^{5}$ between the same discourse and the activities of actors involved in the security issue (governments, companies, organizations, politicians, etc.). This gap proves the absence of the human factor in the treatment of safety problems. The other situation is characterized by the inability of those responsible to perform the actions that should provide safety. The result of this inability is to exclude the human factor from the actions to be taken to achieve the desired and proclaimed safety. In the third

\footnotetext{
4 “The basic constitution" (Heidegger, 1996) and the meaning the same constitutio in everyday life are the aspects of the fundamental structures of human existence.

5 This gap is one of the reasons to elaborate the concept of human security. The concept focuses on human vulnerability and positions the human being as the reference for the discourse and the practice of safety.
} 
situation that denies the human factor, human vulnerability is totally excluded from addressing the safety issues. In other words, the human factor is not part of the discourse, nor is it a considered subject of its practice. What we should do to avoid these situations? How to approach safety in a manner for it to be based on the human factor? The answer is: to put and answer the fundamental questions about safety (Burke, Lee-Koo and McDonald, 2016, pp. 2).

Which questions? First, safety for whom? The question has two aspects. A preventive aspect in the sense of remembering the need to act in accordance with the fact that the human being is the ultimate reason for safety. That is, acting to look for solutions that will not deny the freedom, dignity and integrity of everyone involved in the safety issue. The other aspect concerns the analysis and identification of actors interested in safety for a given situation, taking into account the fact that there are diferent actors interested in safety (civil society, individuals, companies, etc.). To complete our discussion, it is important to note that the above question gained strength after safety became "a product to sell" (Krahmann, 2008, pp. 2). Under such a condition, anyone facing the following questions. Who has a chance to be protected? And by whom? Is safety defined and constituted by whom? These are everyday life questions, not just a subject of academic study or research. They come from the perspective of the human factor as the key to safety, embedded in everyday life.

The human being is defined in terms of freedom. He is a free being in the sense of being able to choose how to think and act in the exposure to the Other ${ }^{6}$. Since this exposure involves human vulnerability, it follows that the human being intends to make choice in the condition of safety. Every person intends to live free of threats to their freedom and to their existence. One comes to the conclusion that safety is not separated from freedom. What is the relationship between safety and freedom? The relationship itself, both in academic discussion and in the daily life, is represented and analyzed in the form of a Safety - Freedom dilemma ${ }^{7}$. How is this dilemma treated today? The most frequent and desirable discourse refers to the balance between freedom and safety. The idea is to identify and establish the 'balance' capable of ensuring safety. This idea understands the need to reduce certain freedoms. In other words, the 'balance' implies the precedence of safety over freedom. It admits placing limits in our freedom in an attempt to identify the 'balance' considered acceptable and efficient in the given context affected by insecurity. In the search for this balance, the efforts are focused on identifying the balance between freedom and safety, giving priority to safety itself. This treatment of the dilemma does not necessarily mean negligence or elimination of the human being as the ultimate reason for safety. In a given situation, this balance means establishing the appropriate and efficient relationship between safety and freedom, prioritizing safety without neglecting or denying the human being. This is confirmed by the idea that the reduction of freedom should be provisional, not permanent. Those responsible for safety can show a willingness to make this reduction longer until it is permanent ${ }^{8}$. The same dilemma also arises in the "authoritarian safety environment", characterized by "extraordinary measures / powers ... that fall outside the norms of the traditional Law" (Pantazis and Pembeton, 2012, pp. 659). In this environment, the discussion about the Safety-Freedom dilemma is neglected, even hindered. Such a scenario may have support from both the authorities and public opinion in the name of safety. The growth of insecurity helps to accept this scenario more and more. Speaking of the Safety Freedom dilemma, it is essential to ask the following: Whose freedom is considered and preserved in the implementation of safety measures in a given situation? Is it of the man seen as the being defined in terms of freedom and characterized by human vulnerability?

\footnotetext{
${ }^{6}$ This is the definition to be used in this study. In general, it indicates the essential of freedom attributed to the human being. $t$ is a definition capable of guaranteeing the comprehension of the problems dealt in this part of our research. It is important to highlight that the possibility of choosing the action happens in the context of exposure to the other. Which means that my freedom is conditioned by the relationship with the other.

${ }^{7}$ An example of this dilemma is the relationship between individual freedoms and national security in the context of combating terrorism. It is a relationship that faces the challenge of identifying and holding "the balance between the provision of individual rights and freed oms and certain national security and safety measures" (Garcia and Geva, 2016, pp. 30).

${ }^{8}$ Governments can show this intention according to the interests of the machinery of the state or of the groups that dominate various spheres of society. In this context, the reduction of freedom is justified by the safety.
} 
Safety involves the consideration and evaluation of the behavior of the actors responsible for security and its consequences for other human beings, that is, it comprehends ethics. Ethical issues like "Who's security? ..., What should we do about the suffering of others? ${ }^{9}$, Could we use force to protect our own safety? ... shape safety debates at all levels, whether individual, or at a state-national, international, or even global level" (Burke, Lee-Koo and McDonald, 2016, pp. 2). Ethics is central to these debates and to the practices of safety. Then one can speak of the safety ethics.

How should we define this ethic?

First, such ethics means considering what we need to do to ensure safety. "What we need to do" means defining and putting into practice the security and safety policies and measures from the perspective of the human being as the ultimate reason for safety. It is a requirement, it has the ethical nature. It helps to employ the policy and measures taken in favor of the human being.

Second, the reflection on the principles and their application to safety practice is necessary. This reflection becomes even more important in cases of use of force in dealing with the safety issue. This is because it could harm the dignity, integrity and freedom of individuals, groups or communiti. The human vulnerability leads to ethical responsibility. It is a condition to exist the ethical responsibility included in the exposure to the Other. To exist not as a desirable ethical discourse, but to meet as a necessity of the existence of the human being.

Third, it is essential to define the "good" in relation to safety. The definition of "good" refers to the values and interests of both those responsible for safety and those who need protection ${ }^{10}$. Which values and interests have priority in the implementation of security and safety policies and measures in a given situation? ${ }^{11}$ In attempting to answer this question, transparency, in the sense of being clear which values and interests have priority, comes as an ethical requirement. Finally, in each particular case, the definition of "good" remains "particularly linked with attempts to recognize the nature and dynamics of progress" (Browning and MsDonald, 2011, pp. 236) in safety. Progress is recognized and evaluated from what has been defined and adopted as the "good" to be achieved by implementing safety polices and measures.

We will finish the discussion on ethics, mentioning a safety issue that came about with the development of information and communication technology. In the focus of the topic is the safety problem of sharing information through networks, which involves the issues of privacy, integrity and security of shared information. Any information shared on the network can be used without the users' consent (Hajli and Lin, 2016: 111) to achieve privacy, steal identity and create the false image of anyone sharing information. It is a behavior that leads to the need to consider it from the ethical perspective, with the goal of protecting users as human beings.

\section{Conclusion}

This study shows the importance of addressing the safety issue from the perspective of human vulnerability seen as an unavoidable dimension of human existence. Any discourse and practices related to the safety problem must involve analysis based on human vulnerability. This means to recognize and understand that the human being is the ultimate reason for any policy and measure implemented to ensure safety in all spheres and in all aspects of life, from the individual to the international and global context.

\footnotetext{
${ }^{9}$ A well-known case, certainly, refers to "the collateral effect." Ethically speaking, this phrase indicates that third parties, exposed to the use of force by those responsible, in charged of applying the measures used in security and safety protection. In this case, what would be the relationship between safety and the death of those who are not part of the situation dealt with by the security and safety measures? It is a question of moral nature.

${ }^{10}$ This is one of the central themes for humanitarian intervention. One decisive aspect concerns the relationship between the values and interests of those responsible for the intervention and the values and interests of the protégés on whose behalf the humanitarian intervention is carried out.

${ }^{11}$ Depending on the actual situation, the definition of priority, interests and collective values or particular interests and values will determine the direction and consequences of implementing security and safety policies and measures in a given situation. The question will be answered differently in the case of collective safety and in the case of "providing safety through the market" (Krahmann, 2008, pp. 389). Precisely because of the fact that different interests and values lead to the definition of priority according to these values and interests.
} 
The importance of such an approach lies in the fact that human vulnerability leads to consideration of the issues that are essential for human existence. They are the human being as the key to safety, freedom as the principle of human existence, and ethical behavior in exposure to Other. In dealing with safety issues, they contribute to the recognition and understanding of the human being as the ultimate reason for safety itself.

In the safety discourse and practices, such recognition and understanding can be neglected, excluded, or mentioned by turning them into only vague words with no relation to reality. Simply from the perspective of daily life comes this question: how to solve this situation to guarantee the freedom, dignity and integrity of everyone as human beings?

\section{References}

[1] J. Busumtwi-Sam, “Contextualizing human security: A 'deprivation-vulnerability' aprouch", Policy and Socity, vol. 27, pp. 15-28, 2008.

[2] H. ten Have, “ Respect for Human Vulnerability: The Emergence of a New Principle in Bioethics", Bioethical Inquiry, vol. 12, pp. 395-408, 2015.

[3] E. Lévinas, Autrement qu'etre ou au-dela de l'essence, The Hague, Netherlands: Martins Nijoff, 1974.

[4] ---------, Totalité et Infini-Essai sur l'extéririte.The Hague, Netherlands: Martins Nijoff, 1971.

[5] B. A. Misztal, The Challenges of Vulnerability, New York, USA: Palgrave, 2011.

[6] C. Cohn, "'Mathernal thiking' and the concept of 'vulerability' in security paradigms, policies and pratics", Journal of International Political Theory, vol. 10, pp. 46-69, 2013.

[7] J. L. Geddes, "Violence and vulnerability: Kafka and Lévinas on human suffering" Literature \& Theology, vol. 29, pp. 400-414, December 2015.

[8] M. Heidegger, Being and Time, Albany, USA: State University of New York Press, 1996. C. Cohn, "'Mathernal thiking' and the concept of 'vulerability' in security paradigms, policies and pratics", Journal of International Political Theory, vol. 10, pp. 46-69, 2013.

[9] A. Burke, K. Lee-Koo and M. McDonald, "An Ethics of Global Security", Journal of Global Security S tudies, pp. 1-19, February 2016.

[10] E. Krahmann, "Security: Collective Good or Commodity?", European Journal of International Relations, vol.14, pp. 379-404, 2008.

[11] C. Pantasis and S. Pemberton, "Reconfiguring Security and Liberty", The British Journal of Criminology, vol. 12, pp. 395-404, 2015.

[12] B. E. Garcia and N. Geva, "Security Versus Liberty in the Context of Counterterrorism", Terrorism and Political Violence, vol. 28. pp. 30-48, 2016.

[13] C. S. Browning and M. McDonald, "The future of critical security studies: Ethics and the politics of security", European Journal of International Relations, vol. 2, p. 235-255, 2013.

[14] N. Hajli and X. Lin, "Exploring the Security of Information Sharing on Social Networking Sites", Journal of Bussiness Ethics, vol. 133, pp. 111-123, 2016. 